\title{
Prediction on New Ship Orders on the Basis of Combination Model
}

\author{
Yu Siqin ${ }^{1, a}$, Xiang Yiye ${ }^{2, b}$ and Jiang Yuantao ${ }^{3, c}$ \\ ${ }^{1}$ School of Economics and Management, Shanghai Maritime University, Shanghai, China \\ ${ }^{2}$ School of Information Engineering, Shanghai Maritime University, Shanghai, China \\ ${ }^{3}$ School of Information Engineering, Shanghai Maritime University, Shanghai, China \\ aysq@163.com, ’’xyy@163.com, jijiangyta@163.coml
}

\begin{abstract}
Keywords: new ship orders; grey system; support vector machine; artificial neural network; combination forecast.
\end{abstract}

\begin{abstract}
When the new ship orders decline deeply and the shipbuilding capability is releasing quickly, how to guarantee the accuracy of prediction of new ship orders becomes the main target for shipbuilding corporate. This paper aims to predict the future demand of new ship with the help of combination forecast model that consist of grey system, support vector machine and artificial neural network. The result showed that combination forecast method is better than single usage of other three methods. The prediction result of new ship orders could provide some useful reference for the development of the shipbuilding industry.
\end{abstract}

\section{Introduction}

According to the statistics from Clarkson, for the last year of 2011, global shipbuilding corporate finished amount of 12.33 million DWT, a decline of 50 percent compared to the same period last year, and received new ship orders of 5.46 million DWT, decreased by 80.8 percent compared to the same period last year. New-Ship orders fell to a six-year low after ship yards completed vessels with a record-high amount of building capacity in 2011. Orders peaked in 2007 and 2008 as ship rents reached all-time highs. Current declines in new ship orders reflect waning demand as a glut of vessels in shipping service weighs on present sheet of tankers, bulk carriers and container ships. The shipbuilding cycle likely reached the peak in 2011. So, there are no orders for new ships in the future years and more contracts are at risk of being delayed or canceled this year.

The new ship orders are impacted on by so many factors, including world trade, shipping profit, world shipping turnover and global economic, and so on that are usually some very complex economic, political and environmental elements [1]. To predict ship orders accurately, the researches looks on the ship industry as a whole system. It assumes that the new ship orders are proportional to the ship industry development. The increasing of ship industry scale would bring up the number of new ship orders, while the ship industry depression would lead to reduce the new ship orders. Another an important characteristic in new ship orders is the time lag between the orders and its deployment in the world ship fleet. If the lag is very large, it would accelerate the change of freight rate in both the increasing and decreasing. This will lead to the ship market risk that new ship orders couldn't match the real ship demand. So, it is very important for shipbuilding corporate to know the developing trend of ship demand in time. To do so, people usually consider some effective prediction method, such as time series, self-response regression, artificial neural network, smoothing method, and even the combination of the above methods. In order to predict the future demand of global new ship, this paper build the combination forecast model that consist of grey system, support vector machine and artificial neural network.

\section{Grey System Prediction Model of New Ship Orders}

Grey system theory, is a new method to analyze unascertained problems with a few data and poor information, that was firstly introduced in early 1980s by Professor Deng Julong [2]. Since then, the theory has been of great concern by academic circles and practitioners, depending on its ability to deal 
with the systems that have partially known and partially unknown information. As the superiority to conventional statistical models, grey model requires only a limited amount of data to describe correctly and monitor effectively the systematic operation behavior. In Grey System theory GM $(1,1)$ model is the most widely used method to predict with the existing data. Based on so many known comprehensive factors it could identify the dynamics situation of a time series in the future.

To develop GM $(1,1)$ model of new ship orders, it is the first step to determine the original input data. By the data in table I the following formula is given.

$\mathrm{y}(0)=(\mathrm{y}(0)(1), \mathrm{y}(0)(2), \mathrm{y}(0)(3), \mathrm{y}(0)(4), \mathrm{y}(0)(5), \mathrm{y}(0)(6), \ldots, \mathrm{y}(0)(19), \mathrm{y}(0)(20))=$

$$
(17.5,33.4,34,31,19.8,33.9,41.3,37, \ldots, 79.1,250,79.2)
$$

Then $\mathrm{y}(0)$ is changed into AGO generation, that is:

$$
\begin{aligned}
\mathrm{y}(1) & =\operatorname{AGOy}(0) \\
\mathrm{y}(1)(\mathrm{k}) & =\sum_{m=1}^{k} y^{(0)}(m)
\end{aligned}
$$

For the parameters a and $\mathrm{b}$ of the $\operatorname{GM}(1,1)$ in $\mathrm{y}(0)$, they are identified by the following formula:

$$
(\mathrm{a}, \mathrm{b}) \mathrm{T}=(\mathrm{BT} \cdot \mathrm{B})-1 \mathrm{BTYN}
$$

Let $\mathrm{B}, \mathrm{YN}$ in recognition formula, there is:

$$
\begin{aligned}
& \hat{a}=\left[\begin{array}{l}
a \\
b
\end{array}\right]=\left(B^{T} \cdot B\right)^{-1} B^{T} Y_{N}=\left[\begin{array}{c}
-0.0349 \\
15310.9
\end{array}\right] \\
& \text { So, } \mathrm{a}=-0.0598, \mathrm{~b}=106.49
\end{aligned}
$$

Then, GM $(1,1)$ gray differential equation model is get:

$$
\mathrm{y}(0)(\mathrm{k})-0.0598 \mathrm{z}(1)(\mathrm{k})=106.49
$$

By bleaching equation, the result is shown in Table 2 .

Using the above method, the new ship orders that we had predicted was 82 (million dwt) in 2012, 93 (million dwt) in 2013.

Table 1 1988-2011 New Orders of ship Unit: (million dwt)

\begin{tabular}{|l|l|l|l|l|l|l|l|l|l|l|l|l|}
\hline \multicolumn{1}{|c|}{ Year } & 1988 & 1989 & 1990 & 1991 & 1992 & 1993 & 1994 & 1995 & 1996 & 1997 & 1998 & 1999 \\
\hline New Order & 17.5 & 33.4 & 34 & 31 & 19.8 & 33.9 & 41.3 & 37 & 36.5 & 54.6 & 40.7 & 50 \\
\hline Year & 2000 & 2001 & 2002 & 2003 & 2004 & 2005 & 2006 & 2007 & 2008 & 2009 & 2010 & 2011 \\
\hline New Order & 69.7 & 55.2 & 52.8 & 117 & 104 & 79.1 & 250 & 79.2 & 140 & 81 & 138 & 62.5 \\
\hline
\end{tabular}

Table 2 GS prediction result Unit: (million dwt)

\begin{tabular}{|c|l|l|l|l|}
\hline Year & 2008 & 2009 & 2010 & 2011 \\
\hline Actual value & 140 & 81 & 138 & 62.5 \\
\hline Predictive value & 117 & 85 & 124 & 116 \\
\hline Erro (\%) & 16.43 & 4.9 & 10.14 & 85.6 \\
\hline
\end{tabular}

\section{Support Vector Machine Model of New Ship Orders}

Support vector machines (SVM), developed by Vladimir Vapnik, are a group of supervised learning methods which could be used to classification, regression, and time series prediction. It has become a hot topic of intensive study due to its successful application in classification tasks and regression tasks, special on time series prediction. The main idea of the new ship orders forecasting is based on the fact that ship purchasing behaviors possess both partially deterministic and partially chaotic properties. The forecasting results could be obtained by reconstructing the deterministic traffic motion and predicting the random behaviors caused by unanticipated factors. 
Suppose a set of training data that are $\left(x_{1}, y_{1}\right), \ldots,\left(x_{i}, y_{i}\right) \ldots,\left(x_{t}, y_{t}\right)$, where each $x_{i} \subset R^{n}$ denotes the input space of the sample and has a corresponding target value $y_{i} \subset R$ for $\mathrm{i}=1, \ldots, \mathrm{t}$ where $\mathrm{t}$ corresponds to the size of the training data. So, future values can be forecasted based on the correlation between the time-variant historical data and its target value. The idea of the new ship orders prediction is to determine a function that can approximate future values accurately. We use data from the first 20 years as the training set and use the last 4 years as our testing set which are in Table 1. In SVM model, a linear function is chosen as the kernel for performance comparison with $\varepsilon=0.01$ and $C=1000$. The SVR experiments were done by running LIBSVM software designed by Lin chih-Jen in Taiwan. The prediction result is shown in table 3. Using the SVM method, the new ship orders was 76 (million dwt) in 2012, 102 (million dwt) in 2013.

Table 3 SVM prediction

Unit: (million dwt)

\begin{tabular}{|c|l|l|l|l|}
\hline Year & 2008 & 2009 & 2010 & 2011 \\
\hline Actual value & 140 & 81 & 138 & 62.5 \\
\hline Predictive value & 132 & 98 & 121 & 88 \\
\hline Erro $(\xi)$ & 5.71 & 20.99 & 12.32 & 40.8 \\
\hline
\end{tabular}

\section{New Ship Orders Prediction Based on ANN}

Artificial neural network (ANN) is a computational model based on the structure and functions of biological neural networks. A neural network through which information flows and affects the structure of the ANN, usually consists of an interconnected group of artificial neurons. This method could find the complex relationships and patterns between inputs and outputs, so it has become a very important research field in which people explore and imitate the intelligent information processing mechanism as brain neural system could do [3]. ANN is composed of a lot of highly interconnected processing elements that is working in unison to deal with specific problems. Based on the new ship orders data from 1988 to 2011 in Table 1, we will use matlab2009 software to achieve neural network algorithm for the new ship orders' prediction.

In order to predict the new ship orders, the standardized data is divided into three groups, namely, neural network input data, output data and test data, the number of hidden layer neurons is critical to determine prediction accuracy and convergence. The factors that affect the new ship orders include global GDP, quantum of international trade and shipping efficiency. So, the input vector is a 3-dimensional one, and the target vector is the forecast result, that is next year's new ship orders. The neurons in the middle layer of the network might be nine. The comparison between predicting and actual values is shown in Table 4. The same method can be used to predict the new ship orders, that is 68 (million dwt) in 2012, 117 (million dwt) in 2013.

Table 4 Artificial neural network prediction Unit: (million dwt)

\begin{tabular}{|c|l|l|l|l|}
\hline Year & 2008 & 2009 & 2010 & 2011 \\
\hline Actual value & 140 & 81 & 138 & 62.5 \\
\hline Predictive value & 111 & 87 & 132 & 67.1 \\
\hline Erro $(\xi)$ & 20.71 & 7.41 & 4.35 & 7.36 \\
\hline
\end{tabular}

\section{Combination algorithm of forecast}

Compared with single forecast methods, the combination forecast method can improve the precision and stability of forecast results, so it is widely used in practice. In general the main purpose of forecasting method is to reduce the squares sum of prediction error [4]. So, it is important how to better determine the weight of individual forecasting method in the composition forecasting method. Many domestic and foreign scholars put forward so many methods to find the weight. These methods include statistics, the recursive method, gray correlation, forecast error matrix, the best fitting and so 
on. The normal methods to generate the component-forecast weights include ordinary-least-squares regression technique, neural network fitting, and so on. In this paper, based on the separate advantage of three prediction methods, the best fitting goodness is used to minimize the squares sum of combination forecasting error, getting the weight of three methods. The fitting equation is:

$$
F=F_{1} * K_{1}+F_{2} * K_{2}+F_{3} * K_{3}+C=F_{1} * 0.102+F_{2} * 0.216+F_{3} * 0.682
$$

The $F_{1}$ is the grey system forecasting result, $F_{2}$ being the value of the support vector machine and $F_{3}$ being the neural network forecast result. $K_{1}, K_{2}$ and $K_{3}$ are the weight of three methods in the combination prediction. The forecasting results are shown in Table 5. Using this method, we can predict new ship orders in 2012 was 72 (million tons • per sea mile), 107(million tons • per sea mile) in 2013.

Table 5 Combination prediction Unit: (million dwt)

\begin{tabular}{|c|l|l|l|l|}
\hline Year & 2008 & 2009 & 2010 & 2011 \\
\hline Actual value & 140 & 81 & 138 & 62.5 \\
\hline Predictive value & 119.91 & 86.36 & 129.46 & 82.65 \\
\hline Erro $(\xi)$ & 14.35 & 6.61 & 6.18 & 32.24 \\
\hline
\end{tabular}

\section{Conclusion}

Comparing the above Table 2, Table 3, Table 4 and Table5, the squares sums of every prediction error from 2008 to 2011 are individually:

Grey system method:

$$
\sum e_{g}^{2}=3603
$$

SVM method:

$$
\sum e_{s}^{2}=1292
$$

Neural network algorithm:

$$
\sum e_{n}^{2}=934
$$

Combination Forecast algorithm:

$$
\sum e_{c}^{2}=911
$$

According to above comparison, we find that combination forecasting method is better than other three methods in the orders prediction on new ship. The reason is mainly that any kind of prediction method has its own law fault and its essential environment. The individual application of any prediction methods will lead to large gap easily. And combination forecasting method is able to adopt an effective part of every model, reducing the gap of separate prediction method. So, in order to fulfill good result in the forecast work, a variety of methods can be utilized on the same project, and furthermore it will be better way to take utilization of combination prediction according to certain combination method.

\section{Acknowledgments}

This work is supported by the Specialized Research Fund for the Doctoral Program of Higher Education, Chinese Ministry of Education (No. 20113121110003) and Innovation Program of Shanghai Municipal Education Commission (No. 12YZ117). 


\section{References}

[1] SCARSI R, The Bulk Shipping Business: Market Cycles and Shipowners' Biases, Maritime Policy \& Manage, Vol.34, No.6 (2007) 577-590

[2] Deng, J. Control Problems of Grey System. Systems \& Control Letters, 1 (1982) 288-294

[3] Manolis Walllace, Ilias Maglogiannis and Kostas Karpouzis. Intelligent One-stop Travel Recommendations Using an Adaptive Neural Network and Clustering of History, Information Technology \& Tourism, 6 (2006) 1-13

[4] Swanson, Norman R \& Zeng, Tian. Choosing among Competing Econometric Forecasts: Regression-Based Forecast Combination Using Model Selection, Journal of Forecasting, Vol. 20, No.6 (2001) 425-430 